\title{
Accumulation of polybrominated diphenyl ethers in breast milk of women from an e-waste recycling center in China
}

\author{
Xinghong $\mathrm{Li}^{1, *}$, Yuan Tian ${ }^{1,2}$, Yun Zhang ${ }^{1,2}$, Yujie Ben ${ }^{1}$, Quanxia $\mathrm{Lv}^{1}$ \\ 1. State Key Laboratory of Environmental Chemistry and Ecotoxicology, Research Center of Eco-Environment Sciences, \\ Chinese Academy of Sciences, Beijing 100085, China \\ 2. Department of Environmental Science and Engineering, Beijing Technology and Business University, Beijing 100048, China
}

\section{A R T I C L E I N F O}

Article history:

Received 8 March 2016

Revised 10 October 2016

Accepted 20 October 2016

Available online 10 November 2016

Keywords:

PBDEs

OH-PBDEs

Human milk

E-waste

\begin{abstract}
A B S T R A C T
Polybrominated diphenyl ethers (PBDEs) can be transferred to infants through the ingestion of breast milk, resulting in potential health risk. In this study, PBDEs, hydroxylated polybrominated diphenyl ethers (OH-PBDEs) and 2,2',4,4',5,6'-hexachlorobiphenyl (CB-153) in human milk from women living adjacent to e-waste recycling sites of Wenling, China, were investigated. The median level of PBDEs in samples from residents living in the e-waste recycling environment $>20$ years $\left(R_{20}\right.$ group, $19.5 \mathrm{ng} / \mathrm{g}$ lipid weight $(\mathrm{lw})$ ) was significantly higher than that for residents living in Wenling $<3$ years $\left(R_{3}\right.$ group, $3.88 \mathrm{ng} / \mathrm{g} \mathrm{lw})(p<0.05)$, likely ascribable to specific exposure to PBDEs from e-waste recycling activities. In the $\mathrm{R}_{20}$ group, most congeners (except for BDE-209) were correlated with each other $(p<0.05)$. Moreover, CB-153 showed significant association with most PBDE congeners, rather than BDE-209. The relationship indicated that most BDE congeners other than BDE-209 shared common sources and/or pathways with CB-153, e.g., dietary ingestion. The correlations between BDE-209 and other congeners were different in the two groups, likely suggesting their different exposure sources and/or pathways for PBDEs. Although estimated dietary intake of PBDEs for infants via breast milk was lower than the minimum value affecting human health, the PBDE exposure of infants should be of great concern because of their potential effect on the development of neonates over long-term exposure. OH-PBDEs were not detected in the collected samples, which is in accordance with reports in published literature, likely indicating that they were not apt to be accumulated in human milk.
\end{abstract}

(c) 2016 The Research Center for Eco-Environmental Sciences, Chinese Academy of Sciences. Published by Elsevier B.V.

\section{Introduction}

Polybrominated diphenyl ethers (PBDEs) are a class of compounds containing 209 congeners. PBDEs have the characteristics of environmental persistence and liposolubility, so their bioaccumulation in environmental samples can easily occur. This bioaccumulation allows PBDEs to be biomagnified in food chains, resulting in elevated levels of these compounds in human beings. Among the commercial PBDE products, penta-, octa- and deca-BDEs are the most commonly used. To date, three commercial formulations of PBDEs have been banned or restricted in the European Union, USA and Canada. However, deca-BDE commercial mixtures are still in widespread use in commercial products and industries in China and many other developing countries in Asia (Ni et al., 2013). Exposure to PBDEs, even in low doses, was reported to have negative

\footnotetext{
* Corresponding author. E-mail: lxhzpb@rcees.ac.cn (Xinghong Li).
} 
effects on the brain development of animal neonates, raising concerns on potential health risks of PBDEs for humans, particularly for children (Darnerud, 2008; Fromme et al., 2016).

With the increasing demand for electronic/electrical products, the amount of electrical and electronic waste (e-waste) has rapidly increased worldwide. An estimated 20-50 million tons of e-waste are generated globally every year (UNEP, 2005), and more than 2 million tons of e-waste are dismantled yearly for metals recycling in Taizhou, a primary e-waste recycling center in China. The e-waste recycling operation in Taizhou is conducted using primitive methods, wherein workers burn piles of wires in open air to remove the coatings on metals, melt circuit boards over coal grills to extract valuable chips (Yu et al., 2006), and then carelessly discard the useless plastics left after fragmentation in the surrounding areas. These unregulated operations and weak control on e-waste products have allowed PBDEs, which have been used worldwide as flame retardants for electronic/electrical products, to be easily transferred to the surrounding environment. As a result, significantly high levels of PBDEs were detected in environmental compartments surrounding the e-waste recycling sites in Taizhou, including sediments and mudsnails (Yang et al., 2009), soil and plants (Zhao et al., 2009b), the atmosphere (Han et al., 2009), and even poultry (Liang et al., 2008). Correspondingly, high levels of PBDEs were also found in human samples taken from local residents, including hair (Zhao et al., 2008), tissue (Zhao et al., 2009a), and blood samples (Zhao et al., 2010). However, only a limited amount of data was available on PBDE levels in breast milk samples from women living in the e-waste recycling sites in Viet Nam (Tue et al., 2010) and in Taizhou, China (Leung et al., 2010). In 2005, a study was performed using five breast milk samples from the women living in Luqiao, Taizhou (Leung et al., 2010). The breast milk samples in that study were found to have a mean concentration of $\mathrm{PBDE}_{\mathrm{S}}$ (including BDE-28, -47, -100, -99, $-154,-153$ and -183 ) of $70.7 \mathrm{ng} / \mathrm{g}$ lipid weight (lw) (ranging from 4.99 to $273 \mathrm{ng} / \mathrm{g} \mathrm{lw}$ ). Although the sample size was small, the result provided evidence that primitive e-waste recycling leads to high PBDE body burdens in local residents. More information on PBDE levels in milk is required in order to assess the health risk of mothers and their infants living in e-waste recycling regions.

Hydroxylated polybrominated diphenyl ethers (OH-PBDEs) are structural analogs of PBDEs. The concern over OH-PBDEs is of particular interest since they elicit a variety of effects in exposed organisms including disruption of thyroid hormone homeostasis, oxidative phosphorylation disruption, altered estradiol synthesis, and neurotoxic effects (Meerts et al., 2001; Marchesini et al., 2008). OH-PBDEs have been found in wildlife tissues (Marsh et al., 2004; Verreault et al., 2005), and human blood (Meijer et al., 2008; Stapleton et al., 2011). To date, there are no data on OH-PBDEs in human breast milk.

It is well known that the body burden of mothers can be related to the chemical levels in breast milk (Schecter et al., 2010; Mannetje et al., 2012). Therefore, it was of great importance to elucidate the mothers' exposure pathway to chemicals in order to protect mothers and their breast-fed infants. To date, the exposure sources and/or pathways of PBDEs in humans have been considered to be diverse, e.g., dust inhalation, dietary ingestion, and inhalation of air (Frederiksen et al., 2009; Ni et al., 2013). However, different from PBDEs, diet was proved to be the primary exposure source of polychlorinated biphenyls (PCBs) in adults (Fernandez-Gonzalez et al., 2015), including the population living in e-waste recycling areas (Xing et al., 2010; Song and Li, 2014). Therefore, the relationship between PCBs and PBDEs might be used to explore the contribution of dietary exposure to the body burden of PBDEs in adults (Bi et al., 2006; She et al., 2007).

Human breast milk is the most important exposure pathway to chemicals for breast-fed infants, so the concentrations of PBDEs and their structural analogs (OH-PBDEs) in the breast milk obtained from women living adjacent to e-waste dismantling sites should be an area of focus. In the present study, we measured the PBDEs and OH-PBDEs in breast milk samples from women living adjacent to the e-waste recycling sites in Wenling Town, Taizhou City, Zhejiang Province, China. Our objective was to investigate the occurrence, explore possible exposure sources/pathways, and assess the potential exposure risks of PBDEs and OH-PBDEs for breast-fed infants in e-waste recycling areas. The information will be useful for evaluating the potential health risk of chemicals from e-waste recycling activities, for future environmental planning and management strategies for e-wastes.

\section{Materials and methods}

\subsection{Sample area}

Taizhou is located at the middle of the coastal area of Zhejiang Province and in the southern tip of the Shanghai Economic Zone in China $\left(28^{\circ} \mathrm{N}\right.$ latitude and $122^{\circ} \mathrm{E}$ longitude). Dismantling operations for e-wastes in this area have been ongoing for 30 years. More than 2 million metric tons of e-wastes are processed in Taizhou annually, and 40,000 people are currently employed in the e-waste dismantling industry. The most intensive e-waste dismantling operations are performed in two towns of Taizhou, Luqiao and Wenling (Fig. 1). A large number of e-waste dismantling household workshops emerged in some villages of Wenling town because of relatively weak

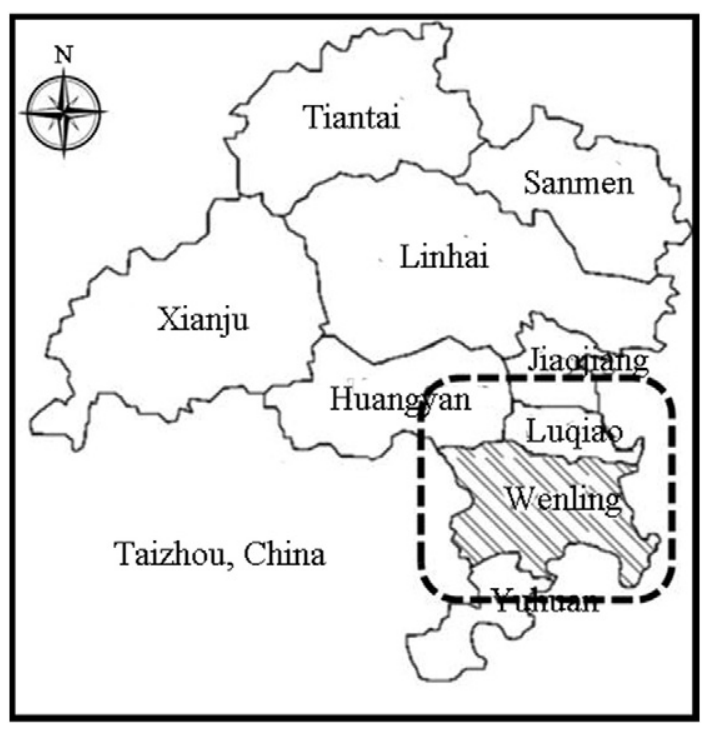

Fig. 1 - Sampling location in Wenling, Taizhou, China. 
environmental policies. As a result, the environmental problems arising from e-waste dismantling are significantly more serious in this town.

\subsection{Sample collection}

Sample collection was conducted from 2012 to 2013. Forty-six breast milk samples were collected from mothers living in Wenling Town, Taizhou City. For the purpose of exploring the effect of e-waste recycling operations on the PBDE body burden of the non-occupational population living in the e-waste recycling regions, the donors were classified as the $R_{20}$ group and $R_{3}$ group based on the length of their residency in the area. The $R_{20}$ group, considered as the exposure group, consisted of twenty-five mothers who did not directly participate in e-waste recycling operations and had >20 years residence time in some Wenling villages heavily involved in e-waste recycling, with a $>10$ years history generally. The $R_{3}$ group, considered as the control group, consisted of twenty-one mothers. The donors in the $\mathrm{R}_{3}$ group had $<3$ years residence time in Wenling, did not live around the e-waste recycling villages and also did not participate in any e-waste recycling activities. After the participant information and consent forms were signed by the donors, questionnaire surveys were conducted to acquire personal information, including age, height, weight, educational level and occupation, residential address, and environmental situation surrounding the residential address (Table 1). There were insignificant differences in demographic factors, including the age, parity, and prepregnancy body mass index, between the subjects in these two groups. The breast milk samples (about $50 \mathrm{~mL}$ ) were collected 21-60 days after delivery, and were then stored in pre-cleaned glass bottles at $-20^{\circ} \mathrm{C}$ until chemical analysis.

\subsection{Extraction and cleanup}

The samples were prepared according to a previously described method (Verreault et al., 2005). In brief, $6 \mathrm{~g}$ breast milk

\begin{tabular}{|c|c|c|}
\hline & $\mathrm{R}_{20}(n=25)$ & $\mathrm{R}_{3}(n=21)$ \\
\hline $\begin{array}{l}\text { Maternal age at delivery (year) } \\
(\text { mean } \pm \mathrm{SD})\end{array}$ & $27.6 \pm 4.4$ & $24.4 \pm 3.5$ \\
\hline Weight (kg) & $53.2 \pm 5.9$ & $54.0 \pm 8.0$ \\
\hline Height $(\mathrm{cm})$ & $158.6 \pm 4.6$ & $153.7 \pm 6.0$ \\
\hline $\begin{array}{l}\text { Pre-pregnancy body mass index } \\
\text { (mean } \pm \mathrm{SD})\end{array}$ & $21.6 \pm 3.1$ & $23.3 \pm 4.3$ \\
\hline \multicolumn{3}{|l|}{ Pre-pregnancy body mass index } \\
\hline$\leq 21 \mathrm{~kg} / \mathrm{m}^{2}$ & $56 \%$ & $48 \%$ \\
\hline$>21 \mathrm{~kg} / \mathrm{m}^{2}$ & $44 \%$ & $52 \%$ \\
\hline \multicolumn{3}{|l|}{ Education level } \\
\hline Lower than high school & $64 \%$ & $83 \%$ \\
\hline $\begin{array}{l}\text { Higher than high school or } \\
\text { equivalent }\end{array}$ & $36 \%$ & $17 \%$ \\
\hline \multicolumn{3}{|l|}{ Occupation } \\
\hline Housewife & $72 \%$ & $44 \%$ \\
\hline Employee & $28 \%$ & $56 \%$ \\
\hline
\end{tabular}

was poured into a $50 \mathrm{~mL}$ screw-top centrifuge tube, and spiked with $2 \mathrm{ng}$ BDE-30, $2 \mathrm{ng}$ BDE-77, $20 \mathrm{ng}{ }^{13} \mathrm{C}_{12}$ labeled $\mathrm{BDE}-209 ; 2 \mathrm{ng}{ }^{13} \mathrm{C}_{12}$ labeled $\mathrm{CB}-153$ used as the internal standard of PBDEs and CB-153; and 5 ng 2'-OH-BDE-28 used as the internal standard of OH-PBDEs. After $2 \mathrm{~mL}$ of $6 \mathrm{~mol} / \mathrm{L}$ $\mathrm{HCl}$ and $5 \mathrm{~mL}$ isopropanol were added, the sample was then ultrasonically extracted in a centrifuge tube with a $20 \mathrm{~mL}$ mixture of methyl tertiary butyl ether (MtBE) and n-hexane $(1: 1, V: V)$ for $5 \mathrm{~min}$. The extraction process was repeated twice. The combined extracts were washed with $20 \mathrm{~mL}$ of $1 \%$ $\mathrm{KCl}$ (wt./vol.) solution, then the organic phase was divided into thirds, with one third used for lipid determination by the gravimetric method. Then, $20 \mathrm{~mL}$ of $1.0 \mathrm{~mol} / \mathrm{L} \mathrm{KOH}$ solution was added to the remaining organic phase (neutral fraction), and the aqueous phase (phenolic fraction) was separated from the neutral fraction three times. The aqueous phenolic fraction was washed thrice with hexane, and the hexane washes were then combined with the neutral organic fraction. The combined neutral extract was dried using $\mathrm{Na}_{2} \mathrm{SO}_{4}$ and then evaporated to $1.0 \mathrm{~mL}$. The aqueous phase (phenolic fraction) was acidified with $\mathrm{H}_{2} \mathrm{SO}_{4}$, and a mixture of Hexane: MtBE $(1: 1, V: V)$ was added to the extracts, with three replications. The combined extract (phenolic fraction) was dried and then evaporated to $1.0 \mathrm{~mL}$. The $\mathrm{OH}$-PBDEs in the extracts were then derivatized as the methoxylated analogs of PBDEs (MeO-PBDEs) with N-Nitroso-N-Methylurea.

The concentrated neutral extract containing PBDEs or methylated OH-PBDEs, respectively, was transferred to a chromatography column (30 cm $\times 10 \mathrm{~mm}$ ID) containing $8 \mathrm{~g}$ sulfuric acid silica ( $30 \%$ acid by weight) and $2 \mathrm{~g}$ of anhydrous sodium sulfate on top. The mixture was then eluted with $50 \mathrm{~mL}$ of dichloromethane:hexane $(1: 1, \mathrm{~V}: \mathrm{V})$. After elution, the sample solution was adjusted to a volume appropriate for gas chromatography-mass spectroscopy (GC-MS) analysis. The injector internal standard $\left({ }^{13} \mathrm{C}_{12}\right.$ labeled $\left.\mathrm{CB}-208\right)$ was added prior to the GC/MS analysis.

\subsection{Chromatographic analysis}

The quantification of PBDEs, CB-153 and OH-PBDEs (measured as methoxylated PBDEs) was performed using an Agilent 6890 GC-5973MSD. The MS analyses were performed in electron capture negative ionization (ECNI) mode. The carrier gas used was helium, with a flow rate of $1.0 \mathrm{~mL} / \mathrm{min}$, and methane was used as the reaction gas.

The separation for PBDEs and CB-153 was performed using a fused silica capillary column (DB-5HT, $15 \mathrm{~m} \times 0.25 \mathrm{~mm}$ ID and $0.1 \mu \mathrm{m}$ film thickness). The GC oven temperature was programmed as follows: the initial temperature was $100^{\circ} \mathrm{C}$ maintained for $2 \mathrm{~min}$, which was then increased to $250^{\circ} \mathrm{C}$ at a rate of $25^{\circ} \mathrm{C} / \mathrm{min}$, followed by a $1.5^{\circ} \mathrm{C} / \mathrm{min}$ ascent to $260^{\circ} \mathrm{C}$, and finally, the temperature was increased at a rate of $25^{\circ} \mathrm{C} / \mathrm{min}$ to achieve the final temperature of $315^{\circ} \mathrm{C}$, which was maintained for $7 \mathrm{~min}$. The injector, transfer line, and ion source temperatures were 250,280 , and $150^{\circ} \mathrm{C}$, respectively. The ion fragments at $m / z 79$ and 81 were monitored for the tri- to hepta-BDE congeners, $\mathrm{m} / \mathrm{z} 488.6$ and 486.6 for BDE-209, $\mathrm{m} / \mathrm{z}$ 360, 362 for CB-153; 492.6 and 494.6 for ${ }^{13} \mathrm{C}_{12}$-labeled BDE-209; $\mathrm{m} / \mathrm{z} 372$, 374 for ${ }^{13} \mathrm{C}_{12}$ labeled CB-153 and 476 and 478 for ${ }^{13} \mathrm{C}_{12}$ labeled CB-208. 
The separation for MeO-PBDEs was performed using a fused silica capillary column (DB-5, $30 \mathrm{~m} \times 0.25 \mathrm{~mm}$ ID and $0.25 \mu \mathrm{m}$ film thickness). The GC oven temperature was programmed as follows: the initial temperature was $80^{\circ} \mathrm{C}$ maintained for $2 \mathrm{~min}$, which was then increased to $290^{\circ} \mathrm{C}$ at a rate of $10^{\circ} \mathrm{C} / \mathrm{min}$, maintained for $20 \mathrm{~min}$. The ion fragments at $\mathrm{m} / \mathrm{z} 79$ and 81 were monitored for the target compounds.

\subsection{Quality control}

The identification of target compounds was based on the retention times and the ratios of the monitored ions relative to the original congener standards. To ensure the accuracy and precision of the analyses, method blanks were run using solvents identical to those used for the real samples. Determination of recovery was made by quantification of target compounds, including eight BDE congeners (BDE-28, -47, -100, -99, -154, -153, -183, and -209), CB-153, and eight OH-PBDEs (3-OH-BDE-47, 2'-OH-BDE-68, 6-OH-BDE-47, 4'-OH-BDE-49, 4-OH-BDE-42, 6'-OH-BDE-99, 4-OH-BDE-90, and 6-OH-BDE-85), added to milk formula solution at $0.2 \mathrm{ng}$ (2 ng for BDE-209). The average recoveries of PBDEs, CB-153 and OH-PBDEs in the three spiked matrix blanks ranged from $69 \%$ to $112 \%$ with relative standard deviation (RSD) $<20 \%$ for PBDEs, $81 \%$ with RSD of $10 \%$ for CB-153, and $71 \%-108 \%$ with RSD $<17 \%$ for OH-PBDEs. The recoveries of the internal standards were $73 \% \pm 9.5 \%$ for BDE-30, $89 \% \pm 5.6 \%$ for BDE-77, $75 \% \pm 23 \%$ for ${ }^{13} \mathrm{C}_{12}$-labeled BDE-209, 93\% $\pm 4.8 \%$ for ${ }^{13} \mathrm{C}_{12}$-labeled CB-153 and $79 \% \pm 15 \%$ for $2^{\prime}-\mathrm{OH}-\mathrm{BDE}-28$. The limits of detection (LODs) were assumed to be five times the noise level, and ranged from 1.1 to $2.4 \mathrm{pg} / \mathrm{g}$ wet weight (ww) for tri- to hepta-BDE, 9.9 pg/g ww for BDE-209, $0.08 \mathrm{pg} / \mathrm{g}$ ww for $\mathrm{CB}-153$ and from 1.8 to $4.5 \mathrm{pg} / \mathrm{g}$ ww for OH-PBDEs.

\subsection{Data analysis}

All the statistical analyses were performed using Statistical Product and Service Solutions (SPSS) 13.0 statistical software (SPSS, Inc., Chicago, IL, USA). The independent samples t-test (Mann-Whitney test) was used to determine the concentration differences between the two groups, and test for differences related to the differences of age, BMI, occupation and education level. The Spearman nonparametric correlation analysis was used to examine the association among compounds in both groups, and between the PBDE level and age information. To minimize the influence of non-detects, the residual values in samples below the LODs were treated as the detected values. A value of $p<0.05$ was considered statistically significant. The profile of $\mathrm{BDE}$ congeners was graphed in OriginPro8 SR0 software (www.OriginLab.com).

\section{Results and discussion}

\subsection{PBDE levels}

Eight congeners of PBDEs, including BDE-28, -47, -100, -99, $-154,-153,-183$, and -209 , were quantified. The concentrations of PBDEs in the samples are listed in Table 2. The total PBDE ( $\sum \mathrm{PBDE}$ ) refers to the sum of eight BDE congeners. The median level of $\sum$ PBDE was $19.5 \mathrm{ng} / \mathrm{g}$ lw for the $\mathrm{R}_{20}$ group and $3.88 \mathrm{ng} / \mathrm{g}$ lw for the $\mathrm{R}_{3}$ group. The $\sum \mathrm{PBDE}$ concentrations in the $\mathrm{R}_{20}$ group were significantly higher than those in the $R_{3}$ group $(p<0.05)$.

For comparison, PBDE levels in breast milk from other countries and regions reported in the published literature are listed in Appendix A Table S1. As shown in Appendix A Table S1, generally, PBDE levels were up to dozens of $\mathrm{ng} / \mathrm{g}$ lw in breast milk samples collected from the general population of the United States and Canada (She et al., 2007), whereas they were $<10 \mathrm{ng} / \mathrm{g}$ lw in samples from the general population of the European countries (Colles et al., 2008; Antignac et al., 2010), Japan (Eslami et al., 2006; Inoue et al., 2006), Russia (Polder et al., 2008), Taiwan (Chao et al., 2010), and Mainland China (Zhang et al., 2011). Clearly, the PBDE concentrations in human breast milk samples measured in the $\mathrm{R}_{20}$ group, were lower than in the US and Canada population (She et al., 2007), where large amounts of PBDE products had been used. However, the median level of PBDEs in the $R_{20}$ group was over 2-fold higher than those in the general population from some developed countries and regions, such as France (Antignac et al., 2010), Belgium (Colles et al., 2008), Japan

Table 2 - Statistical description of PBDE and CB-153 levels in human milk from women living adjacent to the e-waste recycling sites in Wenling, Taizhou (ng/g, lipid weight (lw)).

\begin{tabular}{|c|c|c|c|c|c|c|c|c|c|c|}
\hline \multirow[t]{2}{*}{ Compound } & \multicolumn{5}{|c|}{$\mathrm{R}_{20}(n=25)$} & \multicolumn{5}{|c|}{$\mathrm{R}_{3}(n=21)$} \\
\hline & Range & Mean & S.D. & Median & Geometric Mean (G.M.) & Range & Mean & S.D. & Median & Geometric Mean (G.M.) \\
\hline CB-153 & $9.37-51.8$ & 28.5 & 13.3 & 26.0 & 25.2 & $0.20-8.12$ & 3.95 & 2.55 & 3.74 & 2.63 \\
\hline BDE-28 & $0.19-2.89$ & 1.23 & 0.83 & 0.85 & 0.97 & $0.08-2.05$ & 0.40 & 0.43 & 0.31 & 0.28 \\
\hline $\mathrm{BDE}-47$ & $0.40-29.0$ & 3.05 & 5.56 & 1.83 & 1.77 & $0.17-1.56$ & 0.54 & 0.41 & 0.36 & 0.43 \\
\hline BDE-100 & $0.08-2.83$ & 0.60 & 0.60 & 0.35 & 0.42 & $n d^{a}-0.59$ & 0.13 & 0.14 & 0.09 & 0.09 \\
\hline BDE-99 & $0.12-4.36$ & 1.00 & 0.89 & 0.84 & 0.73 & nd-0.64 & 0.22 & 0.18 & 0.18 & 0.17 \\
\hline BDE-154 & $0.33-22.2$ & 2.32 & 4.35 & 0.84 & 1.18 & nd-0.37 & 0.15 & 0.08 & 0.14 & 0.13 \\
\hline BDE-153 & $2.24-31.6$ & 8.89 & 8.45 & 3.44 & 6.06 & $0.12-4.97$ & 1.58 & 1.26 & 1.07 & 1.06 \\
\hline BDE-183 & $0.39-4.49$ & 1.25 & 1.05 & 0.88 & 0.97 & nd-1.60 & 0.51 & 0.48 & 0.32 & 0.32 \\
\hline BDE-209 & nd-45.0 & 7.37 & 9.01 & 5.01 & 4.95 & nd-16.9 & 3.31 & 3.94 & 2.09 & 2.02 \\
\hline$\sum \mathrm{PBDE}$ & 7.89-90.6 & 25.70 & 20.0 & 19.5 & 20.7 & $1.87-22.0$ & 6.68 & 5.61 & 3.88 & 5.06 \\
\hline
\end{tabular}


(Eslami et al., 2006; Inoue et al., 2006), Russia (Polder et al., 2008), and Taiwan (Chao et al., 2010). Furthermore, the median value was one order of magnitude higher than the background level of PBDEs in Zhejiang Province, China (Shen et al., 2012), and was also higher than those of the general population from other Chinese cities (Zhang et al., 2011). Considering the women with residential time $>20$ years in the $R_{20}$ group and e-waste recycling history $>30$ years in Taizhou, these comparisons indicated that a specific source of PBDEs, that is, e-waste recycling activities in the Taizhou region, likely contributed to the high PBDE levels in the $\mathrm{R}_{20}$ group. When compared with the result for breast milk samples from women living near e-waste dismantling sites in Viet Nam, the PBDE median level found in the $\mathrm{R}_{20}$ group was higher. For the $\mathrm{R}_{3}$ group, the PBDE median level was in the range of those in the general Chinese population.

Eight analogs of OH-PBDEs, including 3-OH-BDE-47, 2'-OHBDE-68,6-OH-BDE-47, 4'-OH-BDE-49, 4-OH-BDE-42, 6'-OH-BDE-99, 4-OH-BDE-90, and 6-OH-BDE-85, were determined in the current study. However, there were no OH-PBDEs found in human milk samples, even the sample with the highest concentration of PBDEs, in this studied population. To our knowledge, although OH-PBDEs have been detected in maternal serum and cord serum (Meijer et al., 2008; Stapleton et al., 2011), so far there have been no reports on OH-PBDEs in human breast milk. Together with the results in this study, these data indicated that $\mathrm{OH}-\mathrm{PBDEs}$ might not be apt to be easily accumulated in human breast milk.

\subsection{Congener profiles of PBDEs}

Fig. 2 shows the profiles of the BDE congeners examined in this study. Regardless of group, both BDE-153 and BDE-209 were the most predominant congeners, accounting for $>60 \%$ of $\sum$ PBDE concentrations. The predominance of BDE-209 and BDE-153 in human milk was similar to results found in human blood and semen sampled recently in the Taizhou region (Zhao et al., 2010; Liu et al., 2012). However, Leung et al. (2010) reported profiles of $\mathrm{BDE}$ congeners with the order $\mathrm{BDE}-47>$ BDE-153 > BDE-28 > BDE-99 (BDE-209 not analyzed), in breast

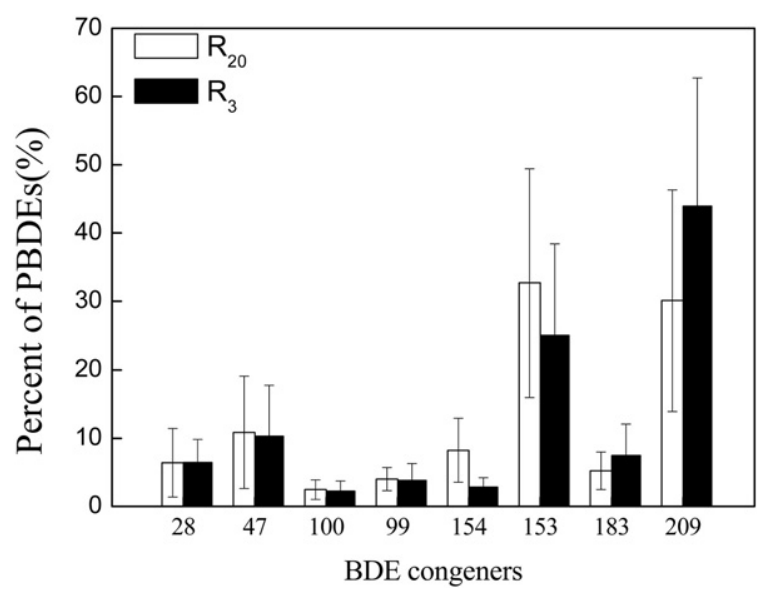

Fig. 2 - Congener profiles of polybrominated diphenyl ethers in the breast milk of women living adjacent to e-waste recycling areas in Wenling, China. milk samples from Taizhou women. That profile, with more abundant BDE-47 compared to BDE-153, was different from the one in this study (BDE-209 excluded). The milk specimens in our study were sampled in 2012-2013 and those in Leung et al.'s study (2010) in 2004-2006, while PBDE technical products evolved from low-brominated PBDEs to deca-BDE in the last decade (Sudaryanto et al., 2008). Moreover, due to its longer half-life relative to BDE-47, -99 and -100 (Geyer et al., 2004; Thuresson et al., 2006), BDE-153 has been found as a more dominant congener compared to BDE-47 or BDE-99 in the general population (Fromme et al., 2016). Possibly, when compared with Leung et al.'s (2010) study, the different profiles reflected the changes in sources and/or the longer term consequences of variability in congener half-lives (She et al., 2007). Deca-BDE recently has been the most commonly used brominated flame retardant in electrical and electronic equipment (Chen et al., 2012), which likely contributed to the predominance of BDE-209 in breast milk.

There were some differences in the relationships of BDE congeners in the $\mathrm{R}_{20}$ group and the $\mathrm{R}_{3}$ group (Table 3 ). In the $\mathrm{R}_{20}$ group, the Spearman nonparametric correlation analysis indicated that BDE-209 was insignificantly associated with other congeners, with the exception of BDE-183. The lack of relationship likely suggested that the debromination of BDE-209 was not likely to be an important source of lower-molecularweight PBDEs in the breast milk samples, and BDE-209 possibly did not share common sources and/or pathways with most other congeners in this population. On the other hand, a significant correlation was found between BDE-209 and other BDE congeners (BDE-100 excluded) in the $R_{3}$ group $(p<0.05)$. The donors in the $R_{20}$ group resided in the e-waste recycling villages, and had a much longer PBDE exposure history related to e-waste recycling activities than those in the $\mathrm{R}_{3}$ group, so this difference in the relationship of BDE congeners likely suggested differences in the PBDE exposure sources and/or pathways in the populations of the two groups.

\subsection{Correlation between $C B-153$ and PBDEs}

E-wastes containing PCBs, such as electric transformers and capacitors, were dismantled in large quantities in Taizhou during the 1980s-1990s, resulting in serious local environment contamination. However, the importing and dismantling of these products have been banned by the Chinese Government since 2000. To the Taizhou population, diet was found to be the primary exposure source for PCBs that accumulated in humans (Liem et al., 2000; Ayotte et al., 2003; Zhao et al., 2007; Xing et al., 2010). In order to assess the possible contribution of dietary exposure to the body burden of PBDEs in the studied population, the relationship between PCBs and PBDEs was analyzed. CB-153, as a representative of total PCB concentrations, was measured in this study because CB-153 has been found to be an indicator of total PCB concentration (Grimvall et al., 1997; Sjodin et al., 2001; Kim et al., 2005; Bi et al., 2006).

In this study, the median level of CB-153 found in the breast milk samples was $26.0 \mathrm{ng} / \mathrm{g}$ lw for the $\mathrm{R}_{20}$ group and $3.74 \mathrm{ng} / \mathrm{g}$ lw for the $\mathrm{R}_{3}$ group. For the $\mathrm{R}_{3}$ group, no correlation was found between $\sum$ PBDE and CB-153 concentrations. Similarly, there was insignificant correlation found between 
Table 3 - Relationships of compounds in human milk from women living adjacent to the e-waste recycling sites in Wenling, Taizhou.

\begin{tabular}{|c|c|c|c|c|c|c|c|c|c|c|}
\hline Compound & BDE-28 & BDE-47 & BDE-100 & BDE-99 & BDE-154 & BDE-153 & BDE-183 & BDE-209 & $\sum$ PBDEs & CB-153 \\
\hline \multicolumn{11}{|l|}{$\mathrm{R}_{20}(n=25)$} \\
\hline BDE-28 & 1.000 & 0.245 & 0.378 & 0.384 & 0.148 & 0.283 & 0.235 & -0.031 & 0.271 & 0.071 \\
\hline BDE-47 & & 1.000 & $.865^{* *}$ & $0.616^{* *}$ & 0.381 & $0.442^{*}$ & $0.552^{* *}$ & 0.222 & $0.678^{* *}$ & $0.488^{*}$ \\
\hline BDE-100 & & & 1.000 & $0.702^{* *}$ & $0.512^{* *}$ & $0.519^{* *}$ & $0.625^{* *}$ & 0.122 & $0.682^{* *}$ & 0.320 \\
\hline BDE-99 & & & & 1.000 & $0.459^{*}$ & $0.672^{* *}$ & $0.673^{* *}$ & 0.219 & $0.788^{* *}$ & $0.415^{*}$ \\
\hline BDE-154 & & & & & 1.000 & $0.656^{* *}$ & $0.492^{*}$ & -0.132 & $0.598^{* *}$ & $0.409^{*}$ \\
\hline BDE-153 & & & & & & 1.000 & $0.729^{* *}$ & 0.132 & $0.895^{* *}$ & $0.483^{*}$ \\
\hline BDE-183 & & & & & & & 1.000 & $0.421^{*}$ & $0.782^{* *}$ & $.0412^{*}$ \\
\hline BDE-209 & & & & & & & & 1.000 & 0.368 & 0.152 \\
\hline$\sum$ PBDEs & & & & & & & & & 1.000 & $0.475^{*}$ \\
\hline CB-153 & & & & & & & & & & 1.000 \\
\hline \multicolumn{11}{|l|}{$R_{3}(n=21)$} \\
\hline BDE-28 & 1.000 & & & & & & & & & \\
\hline BDE-47 & $0.673^{* *}$ & 1.000 & & & & & & & & \\
\hline BDE-100 & $0.629^{* *}$ & $0.684^{* *}$ & 1.000 & & & & & & & \\
\hline BDE-99 & $0.727^{* *}$ & 0.388 & $0.562^{* *}$ & 1.000 & & & & & & \\
\hline BDE-154 & $0.448^{*}$ & $0.622^{* *}$ & $0.618^{* *}$ & $0.479^{*}$ & 1.000 & & & & & \\
\hline BDE-153 & $0.556^{* *}$ & $0.557^{* *}$ & $0.622^{* *}$ & $0.673^{* *}$ & $0.786^{* *}$ & 1.000 & & & & \\
\hline BDE-183 & $0.529^{*}$ & $0.531^{*}$ & $0.587^{* *}$ & $0.712^{* *}$ & $0.740^{* *}$ & $0.944^{* *}$ & 1.000 & & & \\
\hline BDE-209 & $0.650^{* *}$ & $0.523^{*}$ & 0.341 & $0.624^{* *}$ & $0.492^{*}$ & $0.493^{*}$ & $0.486^{*}$ & 1.000 & & \\
\hline$\sum$ PBDEs & $0.625^{* *}$ & $0.560^{* *}$ & $0.571^{* *}$ & $0.738^{* *}$ & $0.731^{* *}$ & $0.827^{* *}$ & $0.852^{* *}$ & $0.817^{* *}$ & 1.000 & \\
\hline CB-153 & -0.152 & 0.123 & -0.074 & -0.057 & 0.399 & 0.275 & 0.322 & -0.017 & 0.086 & 1.000 \\
\hline
\end{tabular}

CB-153 and individual BDE congeners (Table 3). This might suggest differences in the sources and/or pathways of human exposure to PCBs and PBDEs or their differing pharmacokinetics in the human body (Johnson-Restrepo et al., 2005; Bi et al., 2006; She et al., 2007). However, different from the $R_{3}$ group, $C B-153$ was significantly related with $\sum$ PBDE and most BDE congeners (except for BDE-209) in the $\mathrm{R}_{20}$ group. Given that the significant relationship found in the $R_{20}$ group could be ascribed to similar sources and/or exposure pathways for both PCBs and PBDEs, the result possibly suggested the vital contribution of dietary ingestion to $\sum$ PBDE concentrations in breast milk. It was not surprising because, just like PCBs, dietary intake was also the dominant PBDE exposure route for adults living in e-waste recycling areas in Wenling, Taizhou (Jiang et al., 2014). Moreover, it was also worth noting that no association was found between CB-153 and BDE-209 in the $R_{20}$ group (Table 3). This might mean that the sources of human exposure to BDE-209 were different from PCBs. BDE-209 was reported to be the major component of PBDE contamination in the air/dust adjacent to the e-waste dismantling sites in Taizhou (Han et al., 2009; Jiang et al., 2014). Zhao et al. (2009b) also proved that PBDEs from dismantling activities can affect surrounding regions within the range of $50 \mathrm{~km}$ through atmospheric diffusion and deposition. Possibly, the absence of a correlation between CB-153 and BDE-209 indicated the effect of non-dietary exposure, such as contaminated air/ dust from e-waste recycling activities, on the body burden of BDE-209. More evidence is needed to support this conclusion. In all, due to the predominance of BDE-209 in human milk, this suggested that air/dust exposure contributed to the body burden of PBDEs in the population living in the e-waste recycling areas.
The CB-153 level in the breast milk samples from the $R_{20}$ group was notably comparable to those from mothers living near e-waste recycling sites sampled in 2005 (Zhao et al., 2007), and the level did not decrease. Based on the report by Zhao et al. (2007), the levels of the 23 PCB congeners (359 ng/g lw) were approximately one order of magnitude higher than the PBDE levels in the current study, emphasizing the need for continuous focus on PCBs in the Taizhou environment.

\subsection{Correlation of PBDE concentrations with demographic information}

Demographic information on the study population is listed in Table 1. The relationship between the BDE congeners and the demographic information of donors was analyzed. Although a number of reports have shown that PBDE levels increased with increase in maternal age (Chao et al., 2010), Spearman nonparametric analysis showed insignificant correlation between PBDE level and maternal age in the two groups in this study, which was likely attributable to similar PBDE exposure times (approximately 20 years for the $R_{20}$ group and $<3$ years for the $R_{3}$ group) starting when PBDE-containing e-waste dismantling sites rapidly developed in Taizhou in the late 1990s. As reported by Chao et al. (2010), no significant difference was found between the groups with $>21 \mathrm{~kg} / \mathrm{m}$ and $\leq 21 \mathrm{~kg} / \mathrm{m}$ BMI by the Mann-Whitney U test. Similarly, there were insignificant differences found based on occupation and education level.

\subsection{Infant health risk}

The health risks stemming from the contamination of breast milk are issues requiring a great deal of attention. Assuming 
that the average weight of an infant is $5 \mathrm{~kg}$, and the infant consumes $700 \mathrm{~g}$ of breast milk daily (Van Oostdam et al., 2005), the estimated daily intake (EDI) of PBDEs through breast milk can be calculated by multiplying the amount of breast milk consumed by the corresponding PBDE concentration (wet weight), and then dividing the value by the body weight of the infant. In the current study, the EDI of PBDEs in the $\mathrm{R}_{20}$ group was in the range of 1.12-76.9 ng/ $\mathrm{kg} /$ day (median value as $3.61 \mathrm{ng} / \mathrm{kg} /$ day) for BDE-47, 0.32-11.6 ng/kg/day (median value as $1.85 \mathrm{ng} / \mathrm{kg} /$ day) for BDE-99, 2.09-98.9 ng/kg/day (median value as $15.8 \mathrm{ng} / \mathrm{kg} /$ day) for BDE-153, <1.4-120 ng/kg/day (median value as $11.0 \mathrm{ng} / \mathrm{kg} /$ day) for BDE-209, and 15.8-243 ng/kg/day (median value as $45.3 \mathrm{ng} / \mathrm{kg} /$ day) for $\sum \mathrm{PBDE}$. In the $\mathrm{R}_{3}$ group, the ranges were $0.32-5.97 \mathrm{ng} / \mathrm{kg} /$ day (median value as $1.04 \mathrm{ng} / \mathrm{kg} /$ day) for BDE-47, <0.21-1.17 ng/kg/day (median value as $0.38 \mathrm{ng} / \mathrm{kg} /$ day) for BDE-99, 0.44-15.2 ng/kg/day (median value as $2.72 \mathrm{ng} / \mathrm{kg} /$ day) for BDE-153, <1.4-33 ng/kg/day (median value as $5.07 \mathrm{ng} / \mathrm{kg} /$ day) for BDE-209 and $5.43-43.0 \mathrm{ng} / \mathrm{kg} /$ day (median value as $11.4 \mathrm{ng} / \mathrm{kg} /$ day) for $\sum$ PBDE. The maximum acceptable oral dose or reference dose $\left(R_{f} D\right)$ for humans, which is derived from neurobehavioral developmental toxicities and may include altered motor behavior, decreased habituation capability, decreased learning/memory ability, or more serious effects, is $0.1 \mathrm{mg} / \mathrm{kg} /$ day for BDE-47, $0.1 \mathrm{mg} / \mathrm{kg} /$ day for BDE-99, $0.2 \mathrm{mg} / \mathrm{kg} /$ day for BDE-153 and $7.0 \mathrm{mg} / \mathrm{kg} /$ day for BDE-209 (Lyche et al., 2015). Compared with the $R_{\mathrm{f}} \mathrm{D}$, the median values of EDI in the current study were one or two orders of magnitude lower than the reference levels. However, the maximum levels of EDI were $76.9 \mathrm{ng} / \mathrm{kg} /$ day for BDE-47 and $98.9 \mathrm{mg} / \mathrm{kg} /$ day for BDE-153, which were close to value limits. Furthermore, Chao et al. (2007) reported that the PBDE level in the breast milk samples investigated was associated with decreases in the birth outcomes for infants, including birth weight and length, chest circumference, and Quetelet's index, although the EDI of PBDEs (including BDE-17, -28, -47, -66, -85, -99, -100, -138, $-153,-154,-183$ and -209) for a breastfed infant in Taiwan was only $20.6 \mathrm{ng} / \mathrm{kg} /$ day. The EDI median value of PBDEs in the $\mathrm{R}_{20}$ group was over 2 -fold higher than that in the Taiwan study, prompting further concern for the exposure levels of PBDEs and infant birth outcomes in the e-waste recycling environment.

\section{Conclusions}

Our study indicated that women and their infants living adjacent to e-waste recycling areas were exposed to relatively high levels of PBDEs. The high-brominated BDE congeners were predominant in the studied population. Dietary intake was likely to be the major contributor to PBDE levels in human milk from the long-term residents living adjacent to e-waste recycling areas, but the contribution of air/dust from e-waste recycling activities to BDE-209 levels could not be ignored. Although the health risk assessment showed that the infant exposures to PBDEs by the ingestion of breast milk were not above reference levels, more data was required concerning the children's health due to the long-term cumulative effects from PBDE exposure. Because of the demand for the materials and the economic benefits of reclamation, the e-waste recycling industries may be in operation well into the future. This study shows that the mitigation of human health risks and environmental effects resulting from these e-waste activities should be a long-term goal in the future.

\section{Acknowledgment}

This work was supported by the National Natural Science Foundation of China (Nos. 21177152, 21477157).

\section{Appendix A. Supplementary data}

Supplementary data to this article can be found online at http://dx.doi.org/10.1016/j.jes.2016.10.008.

\section{R E F E R E N C E S}

Antignac, J.-P., Cariou, R., Zalko, D., Berrebi, A., Cravedi, J.-P., Maume, D., et al., 2010. Exposure assessment of French women and their newborn to brominated flame retardants: determination of tri- to deca-polybromodiphenylethers (PBDE) in maternal adipose tissue, serum, breast milk and cord serum (vol 157, pg 164, 2009). Environ. Pollut. 158, 3012-3013.

Ayotte, P., Muckle, G., Jacobson, J.L., Jacobson, S.W., Dewailly, E., 2003. Assessment of pre- and postnatal exposure to polychlorinated biphenyls: lessons from the Inuit cohort study. Environ. Health Perspect. 111, 1253-1258.

Bi, X., Qu, W., Sheng, G., Zhang, W., Mai, B., Chen, D., Yu, L., Fu, J., 2006. Polybrominated diphenyl ethers in South China maternal and fetal blood and breast milk. Environ. Pollut. 144, 1024-1030.

Chao, H.-R., Wang, S.-L., Lee, W.-J., Wang, Y.-F., Päpke, O., 2007. Levels of polybrominated diphenyl ethers (PBDEs) in breast milk from central Taiwan and their relation to infant birth outcome and maternal menstruation effects. Environ. Int. 33, 239-245.

Chao, H.A., Chen, S.C.C., Chang, C.M., Koh, T.W., Chang-Chien, G.P., Ouyang, E., Lin, S.L., Shy, C.G., Chen, F.A., Chao, H.R., 2010. Concentrations of polybrominated diphenyl ethers in breast milk correlated to maternal age, education level, and occupational exposure. J. Hazard. Mater. 175, 492-500.

Chen, Y., Li, J.H., Liu, L.L., Zhao, N.N., 2012. Polybrominated diphenyl ethers fate in China: a review with an emphasis on environmental contamination levels, human exposure and regulation. J. Environ. Manag. 113, 22-30.

Colles, A., Koppen, G., Hanot, V., Nelen, V., Dewolf, M.C., Noel, E., Malisch, R., Kotz, A., Kypke, K., Biot, P., Vinkx, C., Schoeters, G., 2008. Fourth WHO-coordinated survey of human milk for persistent organic pollutants (POPs): Belgian results. Chemosphere 73, 907-914.

Darnerud, P.O., 2008. Brominated flame retardants as possible endocrine disrupters. Int. J. Androl. 31, 152-160.

Eslami, B., Koizumi, A., Ohta, S., Inoue, K., Aozasa, O., Harada, K., et al., 2006. Large-scale evaluation of the current level of polybrominated diphenyl ethers (PBDEs) in breast milk from 13 regions of Japan. Chemosphere 63, 554-561.

Fernandez-Gonzalez, R., Yebra-Pimentel, I., Martinez-Carballo, E., Simal-Gandara, J., 2015. A critical review about human exposure to polychlorinated dibenzo-p-dioxins (PCDDs), polychlorinated Dibenzofurans (PCDFs) and polychlorinated biphenyls (PCBs) through foods. Crit. Rev. Food Sci. 55, 1590-1617.

Frederiksen, M., Vorkamp, K., Thomsen, M., Knudsen, L.E., 2009. Human internal and external exposure to PBDEs-a review of levels and sources. Int. J. Hyg. Environ. Health 212, 109-134. 
Fromme, H., Becher, G., Hilger, B., Volkel, W., 2016. Brominated flame retardants - exposure and risk assessment for the general population. Int. J. Hyg. Environ. Health 219, 1-23.

Geyer, H.J., Schramm, K.W., Darnerud, P.O., Aune, M., Feicht, E.A., Fried, K.W., et al., 2004. Terminal elimination half-lives of the brominated flame retardants TBBPA, HBCD, and lower brominated PBDEs in humans. Organohalogen Compd. 66, 3867-3872.

Grimvall, E., Rylander, L., NilssonEhle, P., Nilsson, U., Stromberg, U., Hagmar, L., et al., 1997. Monitoring of polychlorinated biphenyls in human blood plasma: methodological developments and influence of age, lactation, and fish consumption. Arch. Environ. Contam. Toxicol. 32, 329-336.

Han, W.L., Feng, J.L., Gu, Z.P., Chen, D.H., Wu, M.H., Fu, J.M., 2009. Polybrominated diphenyl ethers in the atmosphere of Taizhou, a major e-waste dismantling area in China. Bull. Environ. Contam. Toxicol. 83, 783-788.

Inoue, K., Harada, K., Takenaka, K., Uehara, S., Kono, M., Shimizu, T., et al., 2006. Levels and concentration ratios of polychlorinated biphenyls and polybrominated diphenyl ethers in serum and breast milk in Japanese mothers. Environ. Health Perspect. 114, 1179-1185.

Jiang, H., Lin, Z., Wu, Y., Chen, X., Hu, Y., Li, Y., et al., 2014. Daily intake of polybrominated diphenyl ethers via dust and diet from an e-waste recycling area in China. J. Hazard. Mater. 276, 35-42.

Johnson-Restrepo, B., Kannan, K., Rapaport, D.P., Rodan, B.D., 2005. Polybrominated diphenyl ethers and polychlorinated biphenyls in human adipose tissue from New York. Environ. Sci. Technol. 39, 5177-5182.

Kim, B.H., Ikonomou, M.G., Lee, S.J., Kim, H.S., Chang, Y.S., 2005. Concentrations of polybrominated diphenyl ethers, polychlorinated dibenzo-p-dioxins and dibenzofurans, and polychlorinated biphenyls in human blood samples from Korea. Sci. Total Environ. 336, 45-56.

Leung, A.O.W., Chan, J.K.Y., Xing, G.H., Xu, Y., Wu, S.C., Wong, C.K.C., et al., 2010. Body burdens of polybrominated diphenyl ethers in childbearing-aged women at an intensive electronic-waste recycling site in China. Environ. Sci. Pollut. Res. 17, 1300-1313.

Liang, S.X., Zhao, Q., Qin, Z.F., Zhao, X.R., Yang, Z.Z., Xu, X.B., 2008. Levels and distribution of polybrominated diphenyl ethers in various tissues of foraging hens from an electronic waste recycling area in South China. Environ. Toxicol. Chem. 27, 1279-1283.

Liem, A.K.D., Furst, P., Rappe, C., 2000. Exposure of populations to dioxins and related compounds. Food Addit. Contam. 17, 241-259.

Liu, P.Y., Zhao, Y.X., Zhu, Y.Y., Qin, Z.F., Ruan, X.L., Zhang, Y.C., et al., 2012. Determination of polybrominated diphenyl ethers in human semen. Environ. Int. 42, 132-137.

Lyche, J.L., Rosseland, C., Berge, G., Polder, A., 2015. Human health risk associated with brominated flame-retardants (BFRs). Environ. Int. 74, 170-180.

Mannetje, A., Coakley, J., Mueller, J.F., Harden, F., Toms, L.M., Douwes, J., 2012. Partitioning of persistent organic pollutants (POPs) between human serum and breast milk: a literature review. Chemosphere 89, 911-918.

Marchesini, G.R., Meimaridou, A., Haasnoot, W., Meulenberg, E., Albertus, F., Mizuguchi, M., et al., 2008. Biosensor discovery of thyroxine transport disrupting chemicals. Toxicol. Appl. Pharmacol. 232, 150-160.

Marsh, G., Athanasiadou, M., Bergman, A., Asplund, L., 2004. Identification of hydroxylated and methoxylated polybrominated diphenyl ethers in Baltic Sea salmon (Salmo salar) blood. Environ. Sci. Technol. 38, 10-18.

Meerts, I.A., Letcher, R.J., Hoving, S., Marsh, G., Bergman, A., Lemmen, J.G., et al., 2001. In vitro estrogenicity of polybrominated diphenyl ethers, hydroxylated PDBEs, and polybrominated bisphenol A compounds. Environ. Health Perspect. 109, 399-407.
Meijer, L., Weiss, J., Van Velzen, M., Brouwer, A., Bergman, A., Sauerf, P.J.J., 2008. Serum concentrations of neutral and phenolic organohalogens in pregnant women and some of their infants in the Netherlands. Environ. Sci. Technol. 42, 3428-3433.

Ni, K., Lu, Y., Wang, T., Kannan, K., Gosens, J., Xu, L., et al., 2013. A review of human exposure to polybrominated diphenyl ethers (PBDEs) in China. Int. J. Hyg. Environ. Health 216, 607-623.

Polder, A., Gabrielsen, G.W., Odland, J.O., Savinova, T.N., Tkachev, A., Loken, K.B., et al., 2008. Spatial and temporal changes of chlorinated pesticides, PCBs, dioxins (PCDDs/PCDFs) and brominated flame retardants in human breast milk from northern Russia. Sci. Total Environ. 391, 41-54.

Schecter, A., Colacino, J., Sjodin, A., Needham, L., Birnbaum, L., 2010. Partitioning of polybrominated diphenyl ethers (PBDEs) in serum and milk from the same mothers. Chemosphere 78, 1279-1284

She, J.W., Holden, A., Sharp, M., Tanner, M., Williams-Derry, C., Hooper, K., 2007. Polybrominated diphenyl ethers (PBDEs) and polychlorinated biphenyls (PCBs) in breast milk from the Pacific northwest. Chemosphere 67, S307-S317.

Shen, H.T., Ding, G.Q., Wu, Y.N., Pan, G.S., Zhou, X.P., Han, J.L., et al., 2012. Polychlorinated dibenzo-p-dioxins/furans (PCDD/Fs), polychlorinated biphenyls (PCBs), and polybrominated diphenyl ethers (PBDEs) in breast milk from Zhejiang, China. Environ. Int. 42, 84-90.

Sjodin, A., Patterson Jr., D.G., Bergman, A., 2001. Brominated flame retardants in serum from U.S. blood donors. Environ. Sci. Technol. 35, 3830-3833.

Song, Q., Li, J., 2014. A systematic review of the human body burden of e-waste exposure in China. Environ. Int. 68, 82-93.

Stapleton, H.M., Eagle, S., Anthopolos, R., Wolkin, A., Miranda, M.L., 2011. Associations between polybrominated diphenyl ether (PBDE) flame retardants, phenolic metabolites, and thyroid hormones during pregnancy. Environ. Health Perspect. 119, 1454-1459.

Sudaryanto, A., Kajiwara, N., Tsydenova, O.V., Isobe, T., Yu, H., Takahashi, S., et al., 2008. Levels and congener specific profiles of PBDEs in human breast milk from China: implication on exposure sources and pathways. Chemosphere $73,1661-1668$.

Thuresson, K., Höglund, P., Hagmar, L., Sjödin, A., Bergman, Å., Jakobsson, K., 2006. Apparent half-lives of hepta- to decabrominated diphenyl ethers in human serum as determined in occupationally exposed workers. Environ. Health Perspect. 114, 176-181.

Tue, N.M., Sudaryanto, A., Tu, B.M., Isobe, T., Takahashi, S., Pham, H.V., et al., 2010. Accumulation of polychlorinated biphenyls and brominated flame retardants in breast milk from women living in Vietnamese e-waste recycling sites. Sci. Total Environ. 408, 2155-2162.

UNEP, 2005. E-waste, the hidden side of IT equipment's manufacturing and use. Early Waring on emerging environmental threats no. 5. http://www.grid.unep.ch/ products/3_Reports/ew_ewaste.en.pdf.

Van Oostdam, J., Donaldson, S.G., Feeley, M., Arnold, D., Ayotte, P., Bondy, G., et al., 2005. Human health implications of environmental contaminants in Arctic Canada: a review. Sci. Total Environ. 351, 165-246.

Verreault, J., Gabrielsen, G.V., Chu, S.G., Muir, D.C.G., Andersen, M., Hamaed, A., et al., 2005. Flame retardants and methoxylated and hydroxylated polybrominated diphenyl ethers in two Norwegian Arctic top predators: Glaucous gulls and polar bears. Environ. Sci. Technol. 39, 6021-6028.

Xing, G.H., Wu, S.C., Wong, M.H., 2010. Dietary exposure to PCBs based on food consumption survey and food basket analysis at Taizhou, China-the world's major site for recycling transformers. Chemosphere 81, 1239-1244. 
Yang, Z.Z., Zhao, X.R., Qin, Z.F., Fu, S., Li, X.H., Qin, X.F., et al., 2009. Polybrominated diphenyl ethers in Mudsnails (Cipangopaludina cahayensis) and sediments from an electronic waste recycling region in South China. Bull. Environ. Contam. Toxicol. 82, 206-210.

Yu, X.Z., Gao, Y., Wu, S.C., Zhang, H.B., Cheung, K.C., Wong, M.H., 2006. Distribution of polycyclic aromatic hydrocarbons in soils at Guiyu area of China, affected by recycling of electronic waste using primitive technologies. Chemosphere 65, 1500-1509.

Zhang, L., Li, J.G., Zhao, Y.F., Li, X.W., Yang, X., Wen, S., et al., 2011. A national survey of polybrominated diphenyl ethers (PBDEs) and indicator polychlorinated biphenyls (PCBs) in Chinese mothers' milk. Chemosphere 84, 625-633.

Zhao, G., Xu, Y., Li, W., Han, G., Ling, B., 2007. PCBs and OCPs in human milk and selected foods from Luqiao and Pingqiao in Zhejiang, China. Sci. Total Environ. 378, 281-292.
Zhao, G.F., Wang, Z.J., Dong, M.H., Rao, K.F., Luo, J.P., Wang, D.H., et al., 2008. PBBs, PBDEs, and PCBs levels in hair of residents around e-waste disassembly sites in Zhejiang Province, China, and their potential sources. Sci. Total Environ. 397, 46-57.

Zhao, G., Wang, Z., Zhou, H., Zhao, Q., 2009a. Burdens of PBBs, PBDEs, and PCBs in tissues of the cancer patients in the e-waste disassembly sites in Zhejiang, China. Sci. Total Environ. 407, 4831-4837.

Zhao, Y.X., Qin, X.F., Li, Y., Liu, P.Y., Tian, M., Yan, S.S., et al., 2009b. Diffusion of polybrominated diphenyl ether (PBDE) from an e-waste recycling area to the surrounding regions in Southeast China. Chemosphere 76, 1470-1476.

Zhao, X.R., Qin, Z.F., Yang, Z.Z., Zhao, Q., Zhao, Y.X., Qin, X.F., et al., 2010. Dual body burdens of polychlorinated biphenyls and polybrominated diphenyl ethers among local residents in an e-waste recycling region in Southeast China. Chemosphere 78, 659-666. 